\title{
"Effecting effective and efficient research service strategy for statistical support in Sefako Makgatho Health Sciences University"
}

SUlly Matshonisa Seeletse
Katlego Thabang Mokgwabone

Solly Matshonisa Seeletse and Katlego Thabang Mokgwabone (2016). Effecting

ARTICLE INFO effective and efficient research service strategy for statistical support in Sefako Makgatho Health Sciences University. Environmental Economics, 7(2), 115-121. doi:10.21511/ee.07(2).2016.12

DOI http://dx.doi.org/10.21511/ee.07(2).2016.12

RELEASED ON Friday, 03 June 2016

JOURNAL "Environmental Economics"

FOUNDER LLC "Consulting Publishing Company "Business Perspectives"

NUMBER OF REFERENCES

0
NUMBER OF FIGURES

0

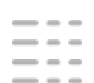

NUMBER OF TABLES

0

(C) The author(s) 2023. This publication is an open access article. 
Solly Matshonisa Seeletse (South Africa), Katlego Thabang Mokgwabone (South Africa)

\title{
Effecting effective and efficient research service strategy for statistical support in Sefako Makgatho Health Sciences University
}

\begin{abstract}
The focus of this paper was to determine research support benchmarks from higher education institutions (HEIs) in South Africa for application in the Sefako Makgatho Health Sciences University (SMU). These benchmarks were sought from networked international HEIs and leading research HEIs in the country. Other benchmarks were sourced from cost-effective models of deployment from other service departments within SMU. The study involved nine HEIs and SMU human resources (HR) department for benchmarking. The study found that the statistics departments were used in these HEIs for major research support. These statistics departments operated from statistics support centres, were supported holistically by their institutions, and were allowed qualified autonomy in their functions. The SMU HR department was assigning individual HR experts to various academic departments for full-time support. The paper combines the models of statistics centres and of assigning HR experts to departments for a new one in SMU. It proposes establishment of a statistical services centre in SMU, in the Department of Statistics and Operations Research (SOR). The centre could be used for statistical training and for fundraising as well. However, the core activities of the centre should be to support research on SMU campus. The centre should operate by dedicating statistics experts to various departments. That model also requires an adequate academic staffing of SOR, as well as initial funding for the entire plans and initial operations of the centre.
\end{abstract}

Keywords: benchmarks, consultation, statistics centre, research leadership, research support.

JEL Classification: I23, I25, L21, L23, L32, M54, O31, O51.

\section{Introduction}

SMU is a university situated in the north-west of Pretoria in the Gauteng Province of South Africa. Its core business is academia, defined as teaching and learning, research, and community service (UL, 2006). Recently, there has been an increasing intake of students at research level doing master's and doctoral degrees. Incompletion rate of postgraduate degrees is, however, notable. Apparently the research component is a major cause of many failures and prolonged studies. Research support is seemingly inadequate, given that there is limited exposure and teaching of research prior to these enrolments. Moreover, the services of statisticians to support the study methodologies and data analyses are also inadequate. Historically, there was a part-time statistician serving in the research office for all the researchers on campus. Recently, there was one full-time statistician in that office catering for the researchers on campus. At both these periods, the researchers at various levels requiring statistical help could calculate over 150 in number, composed of registrars in the medical fields, postgraduates in other fields, as well as campus academics. Currently, the statistician left the post for other opportunities and the research office has no statistician. This simply implies that there is no research support or a dedicated person on SMU campus to support researchers with

(C) Solly Matshonisa Seeletse, Katlego Thabang Mokgwabone, 2016. Solly Matshonisa Seeletse, Ph.D., DBA, Professor, Department of Statistics and Operations Research, Sefako Makgatho Health Sciences University, South Africa.

Katlego Thabang Mokgwabone, Department of Statistics and Operations Research, Sefako Makgatho Health Sciences University, South Africa. statistical services. At campus though, there is the Department of Statistics and Operations Research (SOR) dedicated to developing statistics experts but not tasked to support research. On individual capacity, each SOR lecturer has his own way to obtain markets outside campus to offer statistical services at a fee. This shows that SOR has the capacity to offer SMU statistical services if required.

The past support statisticians in the research office were operating in seclusion, at least from a statistical viewpoint. No other statistician checked the work done by that support statistician. Thus, the work was not quality assured. The other weakness was that the incumbent operated in a statistician free environment. Statisticians grow only when they nurture one another, not in isolation. With the limited research statistical support, some of the researchers have never got a chance to be assisted. As a result, many researchers on campus had to hire external statisticians to assist. Also it was done at a fee. Currently, with the departure of the statistician from the research office, there is even a bigger gap for statistical support. The paper explores the benefits and any disadvantages for dedicating the statistical support services of SMU researchers to SOR.

Experiences and benchmarks from research producing universities (nationally and globally) show that the academic statistics departments serve the research communities of their campuses. This paper discusses the merits and demerits of tasking SOR to take over the services of statistical support for SMU researchers, and the strategies for ensuring effectiveness and efficiency for the campus. 


\section{Research in academia}

Educational institutions are dedicated to disseminate information and knowledge in order to empower people who will, in turn, be engaged in economic activities for advancing national development (Crowther \& Lancaster, 2012). Schools provide basic education while higher education provides advanced education and creates more knowledge. Hence, HEIs can be viewed as the centres dedicated to create knowledge. In South Africa, some HEIs do not participate meaningfully in research. Also, there are academics with doctoral degrees who do not participate in research. Apparently, awarding of some of the doctoral degrees was not based on pure independent research, and there was no insistence on evidence of published work. Hence, there are doctoral degree holders in South African HEIs who cannot even supervise a worthy master's degree in the field to completion. Ideally, a doctoral graduate should eventually supervise up to doctoral level as there cannot be other suitable level for this purpose. As a result, these doctoral graduates lack in capability to undertake independent research, supervising quality research alone (Gay, Mills \& Airasian, 2011). Thus, they need retraining instead of applying for top or management positions in which they become irrelevant, as they are not fit for growing HEIs (Savulescu \& Persson, 2012). They should basically attempt to improve their research capabilities, even when it is to ask for academic research support.

1.1. Academic research support. Many HEIs dedicate an office to support researchers in their campuses (Fouche, 2002). Progressive managers use these opportunities to improve their worth in the work environment. There are, however, still others who ignore these prospects and their selfimprovement. Many of such lame leaders, who are in control positions, tend to delay progress in the departments they lead. Academic managers, such as heads of departments, should be lawfully subjected to holistic improvement, at least in management and research, while serving (Rothwell, 2002). Obliviousness and inexperience in any of these aspects render them unsuitable to head academic departments. One central difficulty for such individuals is to be subjected to obtain empowerment to capable subordinates. They would rather spend money outside campus for being trained, even when they can be educated better on campus. Often they prefer to consult outside campus when funds are available. When there are no funds, they do not consult. However, some of them, whose target is to obtain knowledge, do not mind consulting from subordinates. The baseline is that consulting for assistance is a beneficial attitude to empowerment.
1.2. Consultation services. A generally proven tactic to gain research support is by means of soliciting consultation services. Salls (2007) views consultation approach as building self-character, and transforming oneself from lower capability to elevated capability. Consultation is a way to request support through meetings and discussions. In research, according to Berns (2004), consultations services are used to help and support in one or more of designing or planning research projects, for proposal development, data collection, data analysis and data interpretation. Researchers and academics committed to lifelong learning are always prepared to learn from any source of knowledge. They learn for superiors and subordinates at any slim opportunity they obtain. According to Santrock (2002), they have been developing continually throughout their lives. This could be a way to elevate academics to research leaders.

1.3. Research leadership. Every HEI needs research leaders who are researchers in their own right as well as supervisors of other researches undertaken by others (Crain, 2011; Gay et al., 2011). Research leaders are influential in research as both contributors of new knowledge and also guiding others to become research frontrunners. In some versions, therefore, research leadership refers to research control. Thus, the research leaders can manage poor performance in research in their HEIs. On HEI campuses, Cooper and Curtis (2000) infer that research leaders in the long-run assist in improving research output. Furthermore, by implication, research leaders are skilful in research. They manage and direct their skills for developing their HEIs and their countries (Silli, 2006). Without actual research leadership, HEIs lack in demonstrating research capability and in producing research outputs.

1.4. Research development. The only hard evidence for any research to be adjudged as being publishable is to be published. Personal experiences in boards of examiners' meetings in HEIs have episodes of presiding on cases where some doctoral degrees were passed by external examiners and moderators with a statement that 'they are publishable'. Some comments indicated that there could have been time pressure to submit dissertations and theses for examination. Lack of time could have prevented a publication being completed. According to Schleicher (2011), though, doubts exist in moderators who make such a recommendation for the highest academic qualification based on an assumption and not on proof of work being publishable. Therefore, many doctoral graduates, and particularly those who do not embark in research, should strive to improve as there is no limit to education. 


\section{Research plan}

In any program or task of importance it is vital to design a plan (Keast, 2011). Since academic institutions are required to invent knowledge, they need a plan. Hence, academic institutions should have a research plan. There should be a framework, articulating it and plan to support the broad research goals for academic institutions. Academic institutions need to start and maintain endurance with the strengths of planning processes. The framework should be adaptable to make several changes to help achieve research goals and targets.

2.1. Measure of progress. The framework should enable tracking of progress (Starfiel, 2012). Hence, it should specify performance measures that would designate progress towards identified goals and objectives. These measures should be linked to specific research activities.

2.2. Accountability. The framework should incorporate accountability mechanisms for evaluating the effectiveness of a plan (Williams, 2006). The framework should enable a shift from prior planning processes if necessary. Also iterative approaches should be appreciated. New frameworks should be built on the original ones, but with increased rigor on the planning processes.

2.3. Leadership. The framework should have leaders for programs needed. The leaders should work hard to identify strategic and responsive, relevant goals for the service being planned (Thompson, 2014). Leaders should also specify and allocate a department according to the program. Such home should be relevant, durable and capable of ensuring sustainability.

\section{Research firmness}

Academics in developing countries lack in research skill. The postgraduate degrees are often awarded without evidence of the research work being publishable. This is because research was either not considered predominantly and an operational function of strategic importance or the top managers were themselves not researchers (van Weele, 2005). Members of staff from the academic side could innovate for research resolve, to ensure that they produce quality graduates.

The two extreme issues of centralizing and decentralizing research services can also be entertained when a robust research and statistical support service centre is instituted. With the decentralization approach, according to Wyplosz (2014), a unit manager is responsible for financial result of the business unit. Centralization, on the other hand, is when the corporate level is responsible for every purcha- sing and its decisions (Scott, 2001). This was the approach which failed in SMU with discontinuations and resignations of the incumbents. The latter approach has been the approach within SMU. The Research Office of the SMU was housing the services of a university statistician.

In the case of SMU, the academics could enhance high research output by producing skilful technicians with their postgraduates being forced to produce publishable work and also to publish their work. They should strive for institutions that are firm of research production. They should identify research responsibilities at strategic, tactical and operational levels.

3.1. Strategic level. Academics can propose top management to adopt some research strategy. Here guidelines can be proposed, auditing and reviewing can be planned, investing on research, and research policies can be designed, among others (Rumelt, 2011).

3.2. Tactical level. The tactical level can decide on development and evaluation of ways to effect and improve research (Kiechel, 2010). This is the level at which decisions about research actions and processes are placed.

3.3. Operational level. This level contains daily activities of the initiatives and tasks to be undertaken (Mxkeown, 2012). In research support at SMU, these are actual statistical and research consulting services to the researchers requiring these services.

\section{Skilful management}

The notion of ensuring that academic institutions produce knowledge leads to the inkling that education should produce skilful managers. The proposed centre of this paper should be such that the management of service will be skilful. Hence, the statistical services should be housed and managed at a division where needed available skills can be found. Certain individual attributes and features make the person to be skilful. These include effectiveness, efficiency and the ability to craft strategy.

4.1. Effectiveness. The problem of many organizations is that some work embarked on never reach completion. Also, for various reasons, some results wanted by managers may fail to be realized (Drucker, 2006). Efectiveness is the extent to which objectives are achieved and the magnitude to which targeted problems are addressed. It implies doing the right thing, and is determined without reference to costs. In some instances it is viewed as the capability of producing a desired result.

When something is considered effective, it means that it has an envisioned or probable outcome, or 
produces a profound, intense impression. Therefore, effectiveness entails capability to achieve a purpose. It relates to how well a treatment works in practice, getting the right things done. Also while using a system it can be viewed as the accuracy and completeness of users' tasks.

4.2. Efficiency. The activities in research are often subjected to mistakes, which, ideally, should be avoided or deleted. Efficiency refers to working well without making mistakes or wasting energy (Rumelt, 2011; Wilson, 2012). It is generally regarded as being able to avoid wasting materials, energy, efforts, money, and time in producing a desired result. In more mathematical or scientific terms, it is a measure of the extent to which input is well used for an intended function (output). It often specifically comprises the capability of a specific application of effort to produce a specific outcome with a minimum waste, expense, or unnecessary effort. It is a measurable concept, quantitatively determined by the ratio of useful output to total input. It is basically doing things right.

4.3. Strategy. A service strategy refers to a commitment of services which are provided to clients or buyers of products and services usually for a fee (Kvint, 2016). Freedman (2013) defines a strategy as a comprehensive way to try to pursue high level idea or design to achieve stated goals under conditions of uncertainty. According to Porter (1980), a strategy can be viewed as a broad formula for the manner in which an enterprise is going to compete, what its goals should be, what policies will be needed to carry out those goals, the blend of the goals for which the firm is striving and the policies by which it is seeking to get there.

Strategy is also viewed as a plan, pattern, position, ploy and perspective in a stream of decisions (Mintzberg, 1978; Mintzberg, Ahlstrand \& Lampel, 1998; Mintzberg \& Quinn, 1996). As a plan, strategy refers to a directed course of action to achieve anticipated goals. As a pattern, it refers to a consistent arrangement of behavior patterned to point towards attainment of an objective. As a position, it idealizes locating brands, products, or companies within the market, based on the conceptual framework of consumers or other stakeholders. As a ploy, strategy visualizes a specific maneuver proposed to outfox a competitor. Lastly, as a perspective, executing strategy is based on a model or philosophy of the ideological perspective of the organization.

According to Kvint (2009), a strategy is a system of finding, articulating, and industrializing a principle that safeguards long-term success if followed faithfully. A strategy generally involves setting goals, determining actions to achieve those goals, and mobilizing resources to execute the actions. Therefore, a strategy is about affecting or influencing the future, and is basically the human attempt to obtain to desirable ends with available means. Consequently, a strategy is important because the resources available to achieve these goals are usually limited. The basic notion is that a strategy has to be formulated, and then implemented.

The study propose a support model for researchers in research and statistical services.

\section{Statement of the problem}

Many researchers on SMU campus require statistical services because of the nature of their studies which require statistical methods. In some cases the studies require sophisticated methods that can only be performed by trained statisticians who have completed advanced statistics courses. Over the years the statistical support was an individual posted in the research office, working long congested hours and with no chance of contact with other statisticians. The work of this person was not quality assured by other statisticians, and the person was always inadequate for the masses of researchers requiring statistical support. The results included prolonged studies and some incompletion due to lack of support of statisticians.

\section{Aim and objectives of the study}

The aim of the study is to determine the strategies that SOR can apply in offsetting the problems outlined. The objectives of the study are the following:

- To investigate statistical support of selected top universities.

- To outline the weaknesses of previous SMU approaches on statistical research support.

- To determine advantages and disadvantages of involving SOR in research statistical services support.

- To design cost-effective strategies for SOR to offer statistical services to SMU researchers.

\section{Materials and methods}

7.1. Literature review. Burton (2000) enlightens that literature used innovatively can support practices of research outcomes. The study is a literature study using SMU benchmarks on other services and yardsticks of other universities on their statistical support services. By implication, benchmarks and yardsticks are standards of comparison (Creswell, 2009) and through them new applications and new methods can be developed in environments of interest (Creswell, 2014). On SMU, the human resources (HR) department was used while outside yardsticks 
were the operating statistics departments of some nine top universities in and outside South Africa. The universities' statistical support services of these universities were benchmarked in the way they conduct statistical support for their researchers.

7.2. Population and sample for benchmarking purposes. The HR division of SMU, the current statistics departments of the nine exemplary universities constituted the benchmarked study population. All of them were used in the study to make arguments for the balanced views of the offering of statistical support services by SOR in SMU. According to Creswell (2007), a population can be selected for benchmarking purposes in a purposive sampling approach to ensure relevance and possibility to source available information.

7.3. Data collection and analysis. Data collection consisted of gathering information on the practices of the population members on certain tasks related to the statistical services in SOR. Document analysis was applied in searching for the methods that are used in some of these universities (Braun \& Clarke, 2013). The study sought to unpack the occurrences and structures of the HEIs are benchmarked. Documents, explaining the practices taking place in these universities, were used. Hence, document analysis was used in data analysis for this study.

\section{Results}

The statistical services of all the nine exemplary universities were performed by the academic statistics departments. The services were used for training and development of statisticians and also for ensuring that the work carried out was always statistically assured. No statistical work left the statistics department without having scrutinized by another statistician. Also, several statisticians working on a similar statistical task could generate several alternative approaches. Then the best one would be selected for use on the activity at hand. Many statisticians in training were exposed to such work for their own development. The arrangement was also based on that statisticians should develop as a group, not in isolation.

The departments were fully supported by their respective universities. These were with respect to infrastructure the departments needed, the equipment and software packages as they became fashionable form time to time, the staffing personnel as well as finances, among others. The other observation was that decision-makers sitting in the decision making committees were researchers who had evidence over the years, and they also conducted, supervised and produced research.
These supported departments also linked the statistical support services for researchers with the training of their own statistics students. While they lacked a single way to do it, they all trained their students to do consultation services and perform applied statistical analyses.

The researchers on the campuses were doing well in research. This was the reason they were included in this paper as leaders in research. Hence, the models they have adopted were working for them.

All these exemplary campuses had a long history of research. For many years in the past they had operated in the way they were doing. However, apparently while they were converging to the current forms, they were distracted by their controllers and members in their faculties as they did not want to give autonomy to them. However, it appears that they negotiated their way through external support and their own high performances.

The departments were also given some autonomy in the way they operated, based on the requirements of their client departments and their own feasibility.

These departments' consultation services operated within centres which were formed in departments, managed by members of the departments but not necessarily the heads of the departments (HoDs). A common approach was to have a separate director for the centre who worked closely with the HoD. The centres also enabled operations to extend to clients outside the campuses, and even outside the academic environment. In this way fundraising and profits could be generated through these approaches. The funds generated this way in some campuses assisted to fund developmental programs and opportunities for advanced training of academics and in some case extended to students.

Regarding the HR divisions at SMU and some previous associate campuses of the second author of this paper, each academic department was assigned a dedicated HR expert to deal with any issue regarding HR. These could be advice, support during recruitment and resignations, and any matters that related to staffing. Such support seemed to be effective because there were processes of support and employees were supported and assisted on any HR issue; anytime they needed help and support.

\section{Discussion}

The statistics departments in research producing HEIs reached their current peaks through struggle, and initial lack of support. However, they were determined to achieve all the ingredients of research. They all wanted to be effective and efficient in research. They devised strategies which led to erection 
of centres for statistical and research support. These benchmarked HEIs had been granted some autonomy at research support levels. The models used for their HR, which this paper intends to blend together with research support of statistical services, also seemed to have many advantages in the way staffing was supported. The benchmark campuses in this paper showed relatively impressive levels of operations as well as research outputs based on the national standards.

\section{Conclusion}

Advantages of operating statistical support from centres in the academic departments seem to be vastly beneficial in the support given to campus researchers. On the other hand, the assignment of HR experts to the various departments showed its merits too. Blending the two approaches by opening a statistics service centre for academic research support on SMU campus, and then assigning statistics experts to the departments could, therefore, be a useful approach. This paper proposes such a model, and the details of the idea appear in the next section.
Model formation. SOR department should be fully staffed with all the various subfields of biostatistics (for health and medicine's sake), pure and applied statistics, as well as operations research. Then each academic department in SMU should elucidate its research requirements. SOR would then group common research needs in a single cluster for operation purposes. Then SOR can assign statistics experts or groups of experts to different departments in SMU according to the various interests and experiences of the experts in the research support and consultation services provision.

\section{Recommendations}

This paper recommends that:

- SMU should holistically support ideas and aspirations of SOR for research support.

- A statistics centre should be opened in SMU's SOR.

- Then, the centre should strategically assign its various statisticians to different SMU academic departments requiring statistical research support.

\section{References}

1. Adler, E.S. \& Clark, R. (2011). An invitation to social research: How it's done, $4^{\text {th }}$ edition. Wadsworth: Cengage Learning International Edition.

2. Berns, M.R. (2004). Child, family, school, community, socialisation and support, $6^{\text {th }}$ edition. Wadsworth: Thomson Wadsworth Publishers.

3. Bitner, N. \& Bitner, J. (2002). Integrating technology in the classroom: Eight keys to success, Journal of Technology and Teacher Education, 10(1), pp. 95-100.

4. Bless, C., Higson-Smith, C. \& Kagee, A. (2006). Fundamentals of social research methods: An African perspective. Cape Town: Juta \& Co.

5. Braun, V. \& Clarke, V. (2013). Successful qualitative research: A practical guide for beginners. Los-Angeles: Sage Publications.

6. Burton, D. (2000). 'Using literature to support research. In Burton, O.N. (ed.). Research training for social scientists, Thousand Oaks: Sage, pp. 137-152.

7. Cooper, M. \& Curtis, B. (2000). Managing poor performance handling staff capability issues. Bristol: Network Educational Press.

8. Crain, W. (2011). Theories of development: Concepts and applications, $6^{\text {th }}$ edition. Upper Saddle River: Pearson Education.

9. Creswell, J.W. (2007). Educational research, $3^{\text {rd }}$ edition. Thousand Oaks: Sage Publications.

10. Creswell, J.W. (2009). Research design:Case study. California: Sage Publications.

11. Creswell, J.W. (2014). Research design: Qualitative, quantitative and mixed methods approaches, $4^{\text {th }}$ edition. University of Nebraska, Lincoln. Sage Publications.

12. Crowther, D. \& Lancaster, G. (2012). Research methods, $2^{\text {nd }}$ edition. London: Routledge.

13. Darling-Hammond, L. (1999). Teacher quality and school achievement: A review of state policy evidence. Seattle, WA: Centre for Study of Teaching and Policy.

14. Desimone, L. (2009). Improving impact studies of teachers' professional development: Towards better conceptualizations and measures. Educational Researcher. American Research Association: SAGE publications. Available at: http://er.aera.net (Accessed: April 27, 2016).

15. Drucker, P.F. (2006). The effective executive: The definitive guide to getting the right things done. New York: Collins.

16. Duffy, T. \& Jonassen, D. (1992). Constructivism: New implications for instructional technology. Hillsdale, NJ: Erlbaum. Kenya Institute of Education (KIE) (2005). ICT Teachers' Guide.

17. Fouche, C.B. (2002). Problem formulation. In De Vos, A.S., Strydom, H., Fouche, C.B. \& Delport, C.S.L. (eds.) Research at grassroots. Pretoria: Van Schaiks, pp. 104-112.

18. Freedman, L. (2013). Strategy. London: Oxford University Press.

19. Gay, L.R., Mills, E. \& Airasian, P. (2011). Educational research:Competencies for analysis and application, $10^{\text {th }}$ edition. Upper Saddle River: Pearson Education. 
20. Keast, R. (2011). Joined-up governance in Australia: How the past can inform the future. International Journal of Public Administration, 34(4), pp. 221-231.

21. Kiechel, W. (2010). The lords of strategy. Boston: Harvard Business Press.

22. Kisirkoi, F.K. (2012). Effectiveness of Teacher Advisory Centres (TACs) in teacher professional development in Nairobi county, International Journal of Current Research, 4(4), pp. 297-302.

23. Korol, T. \& Korodi, A. (2011). An evaluation of effectiveness of fuzzy logic model in predicting the business bankruptcy, Romanian Journal of Economic Forecasting, 3, pp. 92-107.

24. Kvint, V. (2009). The global emerging market: Strategic management and economics. London: Routledge.

25. Kvint, V. (2016). Strategy for the global market: Theory and practical applications. London: Routledge.

26. Mckeown, M. (2012). The strategy book. London: Prentice Hall.

27. Mintzberg, H. (1978). Patterns in strategy formation, Management Science (INFORMS), 24 (9), pp. 934-948.

28. Mintzberg, H., Ahlstrand, B. \& Lampel, J. (1998). Strategy safari: A guided tour through the wilds of strategic management. New York: Free Press.

29. Mintzberg, H. \& Quinn, J.B. (1996). The strategy process: concepts, contexts, cases. New York: Prentice Hall.

30. Okuttah, M. (2013). Digital Age: Huge steps towards e-learning in schools. The Daily Nation, 17 October, p. 50.

31. Porter, M.E. (1980). Competitive strategy. New York: Free Press.

32. Rothwell, W.J. (2002). The workplace learner. New York. AMACOM.

33. Rumelt, R.P. (2011). Good strategy/bad strategy. London:Crown Business.

34. Salls, H.S. (2007). Character education-transforming values into virtue. New Jersey: McGraw-Hill.

35. Santrock, J.W. (2002). Lifespan development, $8^{\text {th }}$ edition. New York: McGraw-Hill.

36. Savulescu, J. \& Persson, I. (2012). Unfit for the future: The urgent need for moral enhancement. Oxford: Oxford University Press.

37. Schleicher, A. (2011). Is the sky the limit to education improvement? Phi Delta Kappan, 93(2), pp. 58-63.

38. Scott, G. (2001). Public management in New Zealand: Lessons and challenges. New Zealand, Wellington: Business Roundtable.

39. Silli, B. (2006). Modern approaches in the evaluation of management skill in the mutual fund industry. Universitat Pompeu Fabra, Barcelona, Spain.

40. Simon, M.K. (2002). Probability distributions involving Gaussian random variables. New York: Springer.

41. Starfiel, B. (2012). Primary care: an increasingly important contributor to effectiveness, equity, and efficiency of health services, SESPAS report. Gac Sanit, 26(1), pp. 20-26.

42. Tabachnick, B.G. \& Fidell, L.S. (2007). Using multivariate statistics, $5^{\text {th }}$ edition. Boston: Pearson Education, Inc.

43. Thompson, D.F. (2014). Responsibility for failures of government: The problem of many hands, American Review of Public Administration, 44(3), pp. 259-273.

44. UL (University of Limpopo). (2006). Employment Conditions of Academic Staff, University of Limpopo, Polokwane, South Africa.

45. Van Weele, A. (2005). Purchasing and supply chain management: analysis, planning and practice. London: Thomson.

46. Wackerly, D., Mendenhall, W. \& Scheaffer, R.L. (2008). Mathematical statistics with applications, $7^{\text {th }}$ edition. Belmont, CA, USA: Thomson Higher Education.

47. Wilson, A. (2012). Masters of war: History's greatest strategic thinkers. Newport, RI: The Teaching Company.

48. Williams, R.W. (2006). Leadership accountability in a globalizing world. London: Palgrave Macmillan.

49. Wyplosz, C. (2014). The Eurozone crisis: A near-perfect case of mismanagement, Economia Marche Journal of Applied Economics, 33(1), pp. 2-13.

50. Yin, R.K. (2009). Case study research: Design and methods, $4^{\text {th }}$ edition. Singapore: Sage Publications.

Appendix

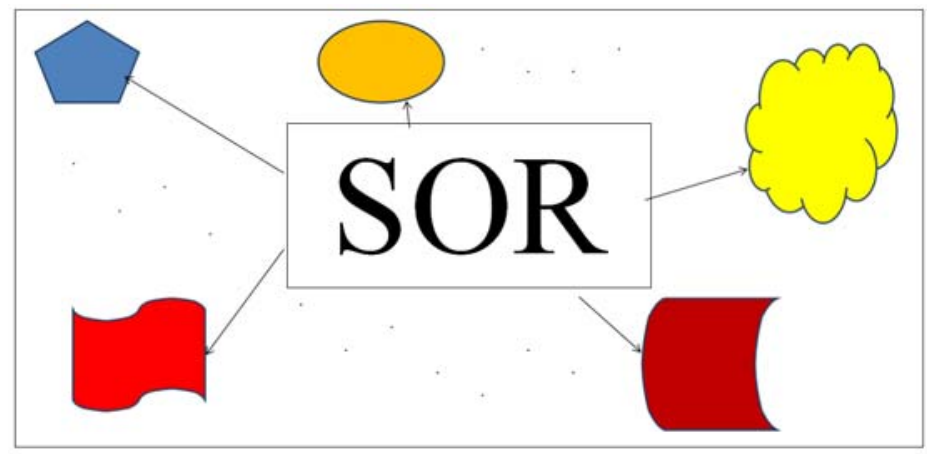

Key: Different insignias indicate diversity of needs and formations as well as overall complexities of the different SMU campus. Dots indicate infiniteness of departments as anticipation of growth. Arrow explains deployment of statisticians from SOR to departments for research support.

Fig.1. Model of SOR research support operation in SMU 